\title{
Exceções e veredas: as ocupações como acontecimento e experiência no Brasil do nosso tempo
}

Eduardo Rebuá*

Universidade do Estado do Rio de Janeiro

Resumo Pensar a articulação cultura, política e educação no atual cenário social brasileiro significa o manejo sensível de categorias, conceitos, mas sobretudo de matizes ontológicos e éticos, que se não representam fotografias micro da totalidade - exercício impossível se entendemos o real como síntese de variados processos e sentidos -, permitem analisar com mais acuidade e aproximação concreta alguns dos fenômenos mais significativos do Brasil contemporâneo. Neste movimento em busca de novas estruturas de sentimento político, ainda que se hibridizem com velhas morfologias da resistência, temos como objetivo compreender em que medida o crescimento, desde Junho (2013), das ocupações de escolas e universidades públicas, bem como de espaços urbanos, notadamente pelos sem teto, apresentam questões, ensaios de experiência, epistemes e encaminhamentos materiais e simbólicos capazes de mobilizar setores da intelectualidade e das lutas sociais menos a partir do par conforto/certeza e mais por conta do deslocamento e da mobilização que esta práxis político-pedagógica engendra. Nosso lastro teórico-metodológico-analítico vale-se sobretudo da contribuição do materialismo histórico, com uma dupla articulação: o conceito de acontecimento em Slavoj Žižek e o de experiência (Erfahrung) em Walter Benjamin, objetivando compreender as ocupações como veredas políticas sob circunstâncias e estruturas cotidianas de exceção.

PALAVRAS-CHAVE: Ocupações; Acontecimento; Experiência. 


\title{
Exceptions and paths: occupations as event and experience in Brazil of our time
}

Abstract An insight about culture, politics and educational articulations in the present brazilian scene means the dealing with cathegories, and concepts but above all the ontological and ethic colors which if not representing micro photos of the whole allows us to understand the real synthesis of several processes and feelings to offer a more accurate analysis and concrete approaching of some of the most significant phenomena of contemporary Brazil.In this movement searching for new political feeling structures, even though mixed with old resistance morphologies, to understand to what extent the growing since Junho (2013), occupations of schools and public universities aswell as urban spaces, mainly by the homeless, show questions, experiences and material knowledges, as symbolic procedures able to mobilize outstanding intelectual people including social fights not only from the comfort/certainty but also from the moving and mobilizations produced by political-pedagogic procedures.Our theoric-metodologic-analytic basis remains, after all, on historic materialism contribution with double articulation: the concept of eventin Zizek and the concept of experience in Benjamim (Erfahrung), aiming to undersrtand the occupations as political paths under circunstances of exceptions.

KEYWORDS: Occupation; Event; Experience.

\author{
Roda gigante eterna \\ Começo sem fim \\ Esse pedaço de chão não é só meu \\ É seu também.
}

[A melhor hora da praia, Nãção Zumbi]

\section{Morfologias da resistência: pensar as ocupações}

Há uma passagem de Saramago em O ano da morte de Ricardo Reis (1984), que diz que o mundo esquece tanto que nem percebe a falta do que esqueceu. Estamos a quatro anos dos eventos chamados de Jornadas de Junho, sendo que a impressão é que o mês que à época parecia não acabar, perdeu força no sentido da permanência e do legado, sobretudo em relação à construção de pautas progressistas. As Jornadas representaram manifestações heterogêneas massivas que eclodiram a partir da questão da mobilidade urbana (especialmente em São Paulo), ampliando-se para outros temas e encarnando a maior mobilização de pessoas na/da história brasileira. Ampliando-se para além daquele mês, tal fenômeno elevou tensões sociais e trouxe às ruas ideologias, lutas e sentidos que pareciam em baixa intensidade no período petista à frente da presidência. Junho de 2013 hibridizou demandas por direitos sociais (transportes, educação, saúde, moradia etc.) e pautas seletivas anticorrupção, além de bandeiras de 
matiz conservador (algumas flertando com símbolos e práticas fascistizantes), mas foi capaz também de ser um termômetro das dinâmicas sociais do/no Estado e da/na sociedade civil brasileira.

Após treze anos do multifacetado e molecular pacto social lulista, capaz de articular, contraditoriamente, reconfigurações hegemônicas regressivas e transformismos, com positivações do popular mais atendimento de demandas sociais há muito adiadas, nos deparamos com um tecido societário ainda esgarçado pelas desigualdades, pelas expressões históricas da questão social, pela lógica da condominização (DUNKER, 2015, p. 47) da existência cotidiana e pelas posturas sintomaticamente apáticas diante das novas-velhas morfologias de golpes (parlamentar, jurídico, midiático, econômico), capazes de remodelar o estado de exceção brasileiro, forma legal daquilo que não pode(ria) ter uma forma legal (AGAMBEN, 2004, p. 12) e resposta histórica das elites nacionais aos conflitos (ou sua iminência) sociais mais agudos, sob faces pseudodemocráticas.

O estado de exceção, que na acepção benjaminiana, em sua oitava tese sobre o conceito da história (BENJAMIN, 2012a, p. 13), caracteriza-se como uma das regras gerais da modernidade capitalista, desde os episódios de $2016^{1}$ tem sido capaz de imprimir derrotas substantivas e velozes em diversas esferas da vida social no país, notadamente naquelas que se vinculam intimamente aos direitos sociais que apontamos acima e às éticas democráticas. Não custa lembrar, ainda sobre as amnésias, que nos últimos anos do Brasil dos anos 2000 temos ouvido, lido e visto, como nenhuma outra vez desde o final da década de 1980, clamores pelo retorno da ditadura e da repressão de Estado, no país que encabeça as listas dos que mais matam mulheres, lincham, prendem pessoas e dilaceram toda e qualquer forma de direitos humanos.

Dentre estas esferas destacamos o campo da Educação, em seus solos mais amplos e mais restritos, como aquele que reúne talvez a maior fragilidade e também a maior capacidade de assimilação de recentes e antigas gramáticas de luta que emergiram do caldeirão da hegemonia, de onde enfatizamos as Jornadas de Junho. Destas formas de ação, defendemos que as ocupações são as mais importantes e com maior capacidade de difusão no espectro das resistências aos processos de comodificação, alienação e esterilização dos espaços de saber.

A ocupação das ruas como tática principal das Jornadas: talvez este tenha sido o principal legado daquele mês que não findou, ainda. Como reverberações desta forma de luta - tão utilizada pelos movimentos sociais no pós-ditadura, principalmente pelo $\mathrm{MST}^{2}$ - tivemos a greve dos garis (2014) na cidade do Rio de Janeiro; as greves dos rodoviários em distintas partes do país, no mesmo ano; a enorme presença do MTST $^{3}$ e de suas ocupações após 2013. Como antídoto para uma ruptura de novo tipo (o Golpe sem Golpe) têm ocorrido ações também de nova roupagem, como as mais de mil (BAVA, 2016, p. 3) ocupações de escolas ${ }^{4}$ Brasil afora por secundaristas, aqueles que muitas vezes passavam ao largo das análises acadêmicas e políticas sobre espaços combativos da sociedade civil. É imperioso, da mesma forma, citar as ocupações nas universidades em várias partes do país, ligadas também às ações empreendidas nas escolas. 
No governo de Michel Temer (PMDB), de baixíssima popularidade, explícito envolvimento com sujeitos e práticas corruptas, e impetuoso ódio à democracia de rosto popular, com seus costumes, equívocos e potências, ao mesmo tempo em que se investe de forma voraz contra símbolos, lutas e conquistas democráticas, se coloca como um defensor da mobilização da apatia e de consensos passivos, inertes à dissolução de direitos, à eliminação de conquistas históricas e ao avanço (neo)conservador. Infelizmente, a partir da memória enquanto crítica, importa afirmar que o lulismo pacto social hegemônico na/da primeira década dos anos 2000 até pelo menos 2013, representando uma nova dinâmica político-social (OLIVEIRA, 2010) - também se mostrou incapaz, ainda que de formas bem distintas, de lidar com o problema democrático de maneiras inventivas, frescas e críticas. Em grande medida o Golpe de 2016 emergiu das contradições não resolvidas do/no lulismo e de suas metamorfoses, que acabaram por engendrar em profusão antíteses do que um dia fora o projeto do Partido dos Trabalhadores:

O governo democrático, diz, é mau quando se deixa corromper pela sociedade democrática que quer que todos sejam iguais e que todas as diferenças sejam respeitadas. Em compensação, é bom quando mobiliza os indivíduos apáticos da sociedade democrática para a energia da guerra em defesa dos valores da civilização, aqueles das lutas das civilizações (RANCIËRE, 2014, p. 11).

Secundaristas e universitários, ao demarcarem posição nos espaços que são seus, a despeito da usurpação cotidiana; ao promoverem novas leituras e sentidos, assim como uma nova práxis político-pedagógica; ao reafirmarem e ressignificarem o caráter público da escola e da universidade, espaços de precariedade, controle, mercantilização, mas também de inventividade e resistência; ao indicarem para a sociedade e para si mesmos que todos(as) são intelectuais, colocando-se publicamente em defesa de seus direitos, dilatam criticamente a esfera pública, em suas múltiplas tonalidades, conferindo um sopro de jovialidade na política, entendida como elaboração coletiva permanente.

O MTST, junto ao MST, que, todavia, diminuiu seu ímpeto durante os anos do lulismo, é talvez o principal movimento social do Brasil em termos de ocupações de espaços públicos, sobretudo para moradias destinadas aos mais pobres. Em Por que ocupamos? o movimento assim afirma: "os sem teto, quando fazem uma ocupação, pretendem a construção de casas para aqueles que precisam. Mas acabam por construir outras coisas também. (...) constroem uma referência de organização coletiva e poder popular" (MTST, 2012, p. 59-60). Talvez possamos afirmar, no calor mesmo desta conjuntura, que o alívio das carências via reformismo fraco (SINGER, 2016, p. 12) e o avanço do par "neo-neo" - neoliberalismo/(neo)conservadorismo - em distintos campos sociais, nesta última década, se por um lado desarmou grandes setores das classes populares, também provocou um retorno aos clássicos da luta social no Brasil, tão (re)visitados na década de 1990, quando a primeira onda neoliberal hegemonizouse no Estado e reprimiu com extrema violência trabalhadores e estudantes do campo e da cidade: a ocupação (como a principal tática de muitos movimentos e coletivos); as passeatas (quase que rebatizadas pelo MST nos anos 1990 e que ainda não saíram de cena); os fóruns (é obrigatória a lembrança dos Fóruns Sociais Mundiais por aqui, 
em Porto Alegre-RS, nos anos de 2001, 2002, 2003, 2005 e 2012) pela moradia, pela educação; os escrachos públicos (que ganharam energias novas com o cinquentenário de Golpe de 1964), as frentes populares (como as atuais Frente Brasil Popular e Frente Povo Sem Medo) etc.

Se em Junho foram as ruas que apontaram e suscitaram caminhos, progressistas e conservadores, hoje parecem ser as recentes ocupações nas escolas (na maior ocupação de espaços escolares da história no país) e universidades, além das ações do MTST, que em um movimento amplo e heterogêneo, sob a liderança ora frágil, ora gigante, de jovens de quatorze, quinze, dezesseis anos, de analfabetos, desempregados, precariados (BRAGA, 2012), que apontam para os problemas da democracia de baixa intensidade (LÖWY, 2016, p. 61) de nossa combalida e frágil república, numa construção plural, porque imprevisível. O que chama a atenção nestas experiências são as veredas democráticas que os sujeitos inesperados, que existem aos milhares em qualquer parte do país, têm forjado, num contexto de aliança entre o liberalismo econômico e o (neo)conservadorismo ${ }^{5}$ cultural.

A ampliação da esfera pública, na defesa concreta dos lugares, sentidos, epistemes e éticas que devem ser de todos, talvez seja o espaço de debate e práxis mais estratégico nestes tempos de ataques à luz do dia contra as classes populares. É preciso que os sujeitos políticos disputem os sentidos públicos de Junho (BRAGA, 2015), que ainda pulsa; disputem os significados das lutas históricas por uma educação pública, gratuita, laica, de qualidade, não homogeneizadora; disputem as experiências educacionais gestadas em espaços acadêmicos formais e/ou populares, que têm se dedicado na elaboração de novas perguntas para antigas questões, sobretudo em relação ao lugar da educação pública hoje; disputem os debates em torno da dimensão pública da vida em sociedade - com destaque para temas como moradia, direitos humanos, saúde, direito à cidade e à cultura - que não é uma chancela do Estado stricto sensu tampouco algo que se elabora com manuais e regras pré-concebidas; e finalmente, que disputem o direito de disputar tudo isso que elencamos, lugar que nunca é de chegada, mas sempre processo e devir, ancorados diuturnamente na memória, que não se apaga como letra no papel.

\section{Veredas democráticas: a ocupação como acontecimento}

Antes de sair dali senti pena, fechei bem a porta

de entrada e joguei a chave num bueiro. Sabe-se lá se

algum pobre diabo não cismava de roubar e se metia

dentro da casa, a essa hora e com a casa tomada.

[Cortázar, Casa tomada]

Nos esforços de disputas políticas e culturais no Brasil de agora, contra um real utilizado como intimidação e submissão, um real verdadeiro e autêntico como o rotulam os sujeitos da hegemonia do capital, devemos opor aquilo que Badiou (2017, p. 9) chama de concreto como bandeira: práxis capaz de se opor aos idealismos, como muitos movimentos antissistêmicos têm feito nos anos 2000 ao criticarem as rea- 
lidades econômicas mundiais, a preponderância do financeiro nos modos de reprodução da vida social, a esterilização das relações sociais, os sofrimentos das existências concretas. Antes mesmo da erosão explícita ${ }^{6}$ do impopular governo de Temer, o movimento massivo de ocupações por secundaristas/universitários e por movimentos sociais renovou a temperatura das lutas nos espaços públicos - desde Junho com pouca intensidade - como quem circunda com as mãos as velas de um bolo de aniversário que começam a se apagar.

Nossa hipótese, a partir da original reflexão de Žižek (2017), é que Junho e a recente retomada de ocupações representam acontecimentos, entendidos como guinada, afetando (modificá-las já é algo mais profundo) a raiz das relações sociais, da suposta normalidade do cotidiano, do inexorável. Como todo acontecimento - ou evento prenhe de singularidade e potência -, em cada momento, é em si mesmo sua própria narrativa (ŽIŽEK, p. 135), é possível lermos estes quatro anos que separam as Jornadas das ocupações de 2016/2017 como uma incubadora de reenquadramentos (ŽIŽEK, p. 175), onde a defesa concreta do espaço público figura como o mais incisivo, sem dúvida. As ruas de 2013, no processo de desgaste e crise do governo de Dilma Roussef, passaram a ser disputadas, política e discursivamente, por setores sociais os mais variados, desde militantes e intelectuais até amplas fatias da classe média, numa polarização binária do espectro político onde "tomar" o espaço do outro parecia anteceder a garantia de seu próprio. Contudo, em comparação com os episódios de Junho, no processo massivo de ocupação das escolas públicas e universidades assistimos todos a um protagonismo de grupos subalternos, com maior ou menor apoio institucional (partidos, sindicatos, grêmios estudantis, diretórios acadêmicos etc.), o que indica uma luta contra as blindagens democráticas materializadas no controle da dimensão pública, sobretudo na escola. Ainda hoje as narrativas e a amplitude destes dois marcos que apontamos permanecem sendo tensionadas, talvez por ainda encarnarem enigma e potência política, concomitantemente.

O mesmo nexo do enigmático com o político pode ser encontrado na literatura fantástica latino-americana, mais precisamente em Casa tomada (1944), de Cortázar, um de seus mais paradigmáticos escritos. Nele é retratado o cotidiano imutável de um casal de irmãos que habitam permanentemente um casarão de Buenos Aires, herança da família rentista e com propriedades e negócios rurais, porém, decadente. Fazer tricô, comer sempre pontualmente, fumar cachimbo, contar o dinheiro guardado: a repetição diuturna amalgamava os dois sob a aura de uma casa que preteritamente fora mais que isso. O clímax do texto se dá quando estranhos invadem uma parte significativa da enorme residência, obrigando seus donos a viverem na parte que isolam do recinto e passam a ocupar. O outro que invade não é definido pelo autor, mas identificado como perigoso e ameaçador, numa casa com feições fantasmagóricas para muitos.

No trato da casa como coisa, Cortázar elabora uma narrativa obscura que permite ao leitor diversas interpretações. Em nossa mirada benjaminiana, trata-se de um olhar sobre a modernidade como um mundo norteado por fantasmagorias: o crescimento da transmutação de todas as relações sociais sob a lógica da mercadoria. $\mathrm{Ou}$ ainda, em uma perspectiva complementar, o declínio da experiência. Em Benjamin a 
corrosão da experiência está ligada à profusão das formas de reificação sob o capital - o conceito marxiano de fetichismo e o lukasciano de reificação, em Benjamin, aparecem como fantasmagoria (KANG, 2009, p. 216) -, expressando-se em dimensões ontológicas várias, como a narrativa, a alteridade e a memória. A casa-propriedade consome as pessoas que ali residem, com suas vidas repetitivas e sem sentido, ao mesmo tempo em que estes moradores consomem a casa-coisa pela reclusão que ali encarnam.

A casa tomada, sob os barulhos e a ameaça constante do que vinha do outro lado, muda e não muda a rotina dos irmãos, até o ponto em que decidem, quase à meia-noite, abandonar o imóvel (aceitando sua ocupação), fechando a porta e jogando a chave no bueiro, pois era deveras perigosa a propriedade de feições fantásticas, de tamanho maior que o de seus habitantes e que continua sendo casa (para os irmãos), ainda que tomada. A ameaçadora casa do centro portenho ameaça até mesmo quem a toma, sejam eles ladrões, pobres, espectros, inimigos, familiares.

Aceitar a tomada da casa, jogando a chave fora, é impedir o quê ou quem? A epígrafe que utilizamos há pouco é exatamente a forma como o conto termina. $\mathrm{O}$ sentimento de pena - pela perda da casa ou dos desconhecidos? - e a referência aos pobres diabos, permitiu para diversos intérpretes, além de outros trechos, análises mais políticas do escrito cortazariano que não serão reproduzidas neste diminuto trabalho. Entretanto, valemo-nos da imagem da casa como espaço disputado, privado ou público, para retomar o tema das ocupações e de sua centralidade nas dinâmicas sociais e educacionais do/no Brasil contemporâneo. Em qual parte do texto podemos (re) enquadrar as lutas sociais contra-hegemônicas no Brasil dos anos dois mil? A casa amorfa e inalcançável? A casa invadida e disputada de formas distintas e em espaços vários? A casa tomada, sem a chave e desabitada por seus antigos proprietários? Uma casa tomada sob a forma leminskiana ${ }^{7}$ do beco com saída, ainda que com uma porta sem chave?

Como acontecimento político, as ocupações têm sido capazes de tomar não apenas espaços públicos taxidermizados, mas também narrativas e comunicabilidades da experiência, não expulsando seus tradicionais moradores, mas incomodando-os a ponto de se deslocarem para outros cômodos isolados da casa. A repressão sobre os secundaristas foi muito menor do que se costuma ver nas universidades, nas passeatas ou mesmo nas ações do MTST. Mesmo estes últimos, se estabelecemos uma rápida comparação com a violência perpetrada contra as ocupações e passeatas do MST nos anos 1990, ápice destas ações, têm sido capazes de resistir de formas inventivas e constrangedoras para os representantes da burguesia nacional via sociedade política ou sociedade civil. Retirar os sem teto de um prédio abandonado no centro de São Paulo é muito mais desgastante e socialmente problemático que expulsar trabalhadores sem terra de propriedades agrárias no interior do país. Quem rouba e quem toma uma propriedade?

Jovens estudantes e pessoas destituídas do direito à moradia preenchem de sentido, dúvidas e de uma práxis político-pedagógica estas casas vazias do espaço público, cada vez mais privatizado, cindido e invisível aos rostos humanos. Fortalecendo a experiência da partilha e trasladando o par perigo/ameaça da casa tomada, dos sujeitos 
que a tomam, para aqueles que a concentram, esterilizam e fenecem, assim como para a lógica da reificação, os artífices das ocupações do público em todo o país elaboram outras alteridades e renovam a política como expressão da experiência do sensível.

\section{Lutas e sentidos: a ocupação como experiência}

$\mathrm{Na}$ tessitura empreendida até aqui objetivamos articular dois grandes eixos teórico-analíticos da sociedade brasileira hodierna: (i) as hegemonias vigentes e as (ii) alternativas de resistência democráticas sintonizadas com a dinâmica do tempo histórico e das classes subalternas. No centro de nossa abordagem identificamos um contexto extremamente adverso para as lutas sociais contra-hegemônicas que ensaiam novas formas ético-políticas (...) novas iniciativas (GRAMSCI, 2006, p. 314), como as ocupações: a) o par neoliberalismo-neoconservadorismo, antigos parceiros hegemônicos reoxigenados numa onda conservadora (BOULOS, 2016, p. 29) sem precedentes no pós-ditadura; e (b) o incremento da democracia blindada (DEMIER, 2017, p. 40), face da democracia liberal que regula seus núcleos políticos de decisão (parlamento, mídia, judiciário, $\mathrm{ONG}$ 's, partidos, think tanks ${ }^{8}$ ) quase que impermeáveis às demandas populares.

Como novas-velhas formas de enfretamento político, as ocupações, que ganham novo ímpeto a partir dos eventos de Junho e das recentes ações de estudantes secundaristas/universitários (com destaque para os primeiros), são analisadas nestes escritos como a materialização da política enquanto forma de experiência (RANCIÈRE, 2009, p. 16), mas não a experiência como conjunto de vidas ou vivências - Erlebnis, segundo Benjamin -, mas como construção coletiva de sentidos, ou seja, a Erfahrung benjaminiana: aquilo que nos afeta profundamente, que nos significa, nos sensibiliza, articulando memória, narrativa e temporalidade com uma potência única.

Presente em diversos momentos de sua obra, a experiência em Walter Benjamin vai ganhando maturação e um lastro dialético-materialista à medida em que o próprio crítico alemão "experiencia” os anos 1920 e 1930, sendo nesta última década o momento em que tal conceito ganha a forma mais incisiva e sensível à dinâmica histórica do jetztzeit (tempo-de-agora), quando Benjamin termina Experiência e pobreza (2012b), em 1933, ano da ascensão de Hitler ao poder como chanceler; e O narrador (1987), em 1936, quando ocorre a maior antessala da Segunda Guerra Mundial, a Guerra Civil Espanhola (1936-1939).

Em meio às ruínas da modernidade, esterilizadora de alteridades/narrativas e aprofundamento das novas barbáries, encontra-se o escombro da experiência, o que dela sobrou. A catástrofe permanente enterra não apenas sujeitos históricos e temporalidades, mas também a capacidade de partilharmos saberes, práticas, subjetividades, sentimentos, principalmente nossa capacidade de conferir sentido ao que nos ocorre. Nossa pobreza, efeito direto da nova barbárie cotidiana do mundo forjado pela burguesia à sua imagem e semelhança, é principalmente uma pobreza da experiência, da capacidade de construir sentidos sobre o real. "Na verdade, de que nos serve toda a cultura se não houver uma experiência que nos ligue a ela?” (BENJAMIN, 2012b, p. 86). E de que vale toda a cultura se ela não fizer sentido, acrescentamos?! 
Entendemos que "experienciar" em Benjamin significa construir, partilhar e recuperar sentidos sobre a própria existência e sobre o mundo. Para ele era inadiável o desenvolvimento de um conceito elevado de experiência, capaz de fugir da abstrata oposição entre sujeito e objeto: um conceito de experiência capaz de corresponder às necessidades humanas de uma existência plena de sentido (KONDER, 1999, p. 26). A experiência benjaminiana sintoniza-se com o coletivo (MITROVITCH, 2011, p 126-127), numa dialética entre homem e mundo, norteada pelo contexto social e pelas condições materiais e subjetivas de cada época histórica.

Assim, se a experiência é coletiva, logo, a elaboração de sentidos é também um processo plural, bem como multifacetado, irregular, difuso, histórico. Defendemos que sentido, no singular, pode dar a ideia do sentido unívoco do romance (forma narrativa típica da sociedade burguesa, segundo Benjamin) ou seja, da busca de apenas uma explicação para a vida, a morte, a história: o sentido como fim. Falamos de sentidos, no plural, como significações individuais e/ou coletivas, concepções de mundo, impressões sobre o existir, forjadas e ressignificadas cotidianamente a partir da(s) experiência(s) partilhada(s) com o(s) outro(s), mas abertas e não fechadas como fim - o sentido como o "sendo" (processo).

As ocupações de espaços públicos, em seu encontro com o real, experimentado e medido pela subjetividade, constituem experiências do sensível que de muitas maneiras atingem as angústias dos sujeitos históricos no capitalismo periférico brasileiro, neste processo de crise do pacto social lulista e do reforço das hegemonias neo-neo. Parafraseando Badiou (2017, p. 14), "essa experiência toca tanto mais no real na medida em que assume o risco da angústia que se sente se ele vem a faltar ou, pelo contrário, a superabundar". Para o filósofo francês, a angústia encarna um encontro com o real, que só é alcançado na medida em que é desmascarado (Ibidem, p. 23). O real é sempre algo que desmascaramos.

Arrancar a máscara representa, para Badiou, um acontecimento (2017, p. 28), indo ao encontro da categoria žižekiana aqui apresentada. No capitalismo o semblante mais vigoroso é a democracia liberal, ao ponto de que saídas e bandeiras democráticas (as democracias odiadas) em momentos de crise, como ocupar uma praça ou uma prefeitura, têm sempre sua linguagem e forma de ação rotuladas como violentas. Costurando Badiou e Benjamin (2013), o rótulo traduz efetivamente o que a ocupação representa para as hegemonias vigentes sob o capitalismo: o acesso ao real via subtração de sua face mascarada será sempre uma práxis violenta, tendo em vista que é a violência quem instaura o direito dominante, que dialeticamente é a violência dominante materializada.

Temos esquecido da centralidade das ocupações em muitas de nossas elucubrações acadêmicas e diagnósticos político-sociais. Notar a falta do que temos esquecido, como na reflexão de Saramago, significa, no caso das ocupações, resgatar talvez a experiência mais robusta como criação de sentidos coletivos e de partilha da política. As lutas no capitalismo tardio não podem ser sintetizadas em uma única esfera tampouco em uma só espacialidade/temporalidade. Todavia, há que se focalizar nos acontecimentos e experiências mais capazes do curto-circuito nas formas éticas, estéticas e políticas da hegemonia enquanto equilíbrio instável. 
Tomar a casa pode ser o primeiro passo para impelir seus donos ao movimento imprevisível - mas nunca inesperado -, antes da chave ser jogada no bueiro. Começar pelos fundos, por onde os invasores acessam o imóvel no conto de Cortázar, pode ser a maneira mais inventiva de desmascaramento do real capitalista, tantas vezes invisível porque ainda não ficcionado.

\section{Considerações finais}

Ainda que a exiguidade deste espaço para uma conclusão, dada a ênfase que optamos em conferir ao debate, acabe nos impelindo, de forma positiva, para considerações finais em caráter de abertura, entendemos que é possível apresentar, numa aproximação ao mesmo tempo panorâmica e minuciosa, que a preocupação com a experiência como elaboração, complexa e coletiva de sentidos, corresponde à marca mais sensível que objetivamos imprimir ao tratar dos processos recentes de ocupação de espaços públicos no país: as ruas heterogêneas de Junho, ainda um ponto cego para muitos analistas e teorias; as escolas, que trouxeram à cena política jovens que só costumam aparecer nos mass media quando em preparação para o ENEM (Exame Nacional do Ensino Médio) ou em seus conflitos existenciais; os espaços tomados pelo MTST em todo o país, aqueles lugares que só se tornam visíveis quando escandalizados, compreendendo o escândalo como o revelar de um pedacinho do real (BADIOU, 2017, p. 15).

Os sujeitos de Junho, os jovens secundaristas/universitários brasileiros e os sem teto, talvez no contexto mais dramático da dimensão pública da vida social brasileira desde o final do regime civil-militar, quando maiúsculas hegemonias disputam pujantemente os rumos políticos, econômicos, pedagógicos e filosóficos dos espaços de poder, de saber, de morar, têm sido capazes de criar e/ou recuperar morfologias de lutas, derrotadas ou vitoriosas; discursos políticos que ensaiam novidades em meio à velharia que a juventude costuma entender como outsider (carros de som com jingles cristalizados ou jograis, por exemplo); práticas democráticas comumente exógenas ao ambiente escolar público, como os coletivos de cultura, as rodas de debate, as ocupações, passeatas, os fóruns; e finalmente, as experiências que não são apenas vivências de algo fugaz, transitório, mas ações prenhes de sentido e de dúvidas, outro visitante cotidianamente indesejado nas salas de aula, nos grêmios estudantis, nos diretórios e centros acadêmicos, nas formações (des)continuadas, nos departamentos da universidade. Experiências políticas nos termos da erfahrung, capazes de promover partilhascomunidade, frear as fragmentações e a mudez, promover permanências e engendrar memórias plenas de significado, porque organicamente vinculadas a práxis humana.

Na dinâmica multifacetada da periférica sociedade brasileira destes anos dois mil, capaz de misturar demandas e sentidos novos com bandeiras e símbolos de temporalidades em preto-e-branco, num perigoso jogo dicotômico e dicotomizador entre o agora e o ontem, cuja síntese tem sido majoritariamente mais à direita do espectro político, é imprescindível partir, como afirmou o próprio Benjamin (BENJAMIN, 1998, p. 11) em relação à obra brechtiana, não das boas coisas velhas, mas sim das más coisas novas. Más porque nos interpelam, deslocam e provocam reflexões impertinentes e, por isso, inadiáveis. 


\section{Referências}

AGAMBEN, Giorgio. Estado de exceção. 2. ed. São Paulo: Boitempo, 2004.

BADIOU, Alain. Em busca do real perdido. 1. ed. Belo Horizonte: Autêntica Editora, 2017.

BAVA, Silvio Caccia. O Brasil será o Paraná?. In: Le Monde Diplomatique Brasil, ano 10, número 112, novembro 2016.

BENJAMIN, Walter. O narrador. Considerações sobre a obra de Nikolai Leskov. In: Magia e técnica, arte e política: ensaios sobre literatura e história da cultura (Obras escolhidas v. 1). 3 . ed. São Paulo: Editora Brasiliense, 1987. p. 197-221.

BENJAMIN, Walter. Understanding Brecht. New York, London: Verso, 1998.

BENJAMIN, Walter. Sobre o conceito de história. In: O anjo da história. 1.ed. Belo Horizonte: Autêntica Editora, 2012a. p. 7-20.

BENJAMIN, Walter. Experiência e pobreza. In: $\mathbf{O}$ anjo da história. 1.ed. Belo Horizonte: Autêntica Editora, 2012b. p. 83-90.

BENJAMIN, Walter. Para a crítica da violência. In: Escritos sobre mito e linguagem (19151921). 2.ed. São Paulo: Duas Cidades; Editora 34, 2013.p. 121-156.

BOULOS, Guilherme. A onda conservadora. In: DEMIER, Felipe; HOEVELER, Rejane (orgs.). A onda conservadora: ensaios sobre os atuais tempos sombrios no Brasil.1. ed. Rio de Janeiro: Mauad X, 2016. p. 29-31.

BRAGA, Ruy. Os sentidos de Junho. Blog Junho, 2015. Disponível em: <http://blogjunho. com.br/os-sentidos-de-junho/>. Acesso em: dez. 2017.

CORTÁZAR, Julio. Bestiário. 4a ed. Rio de Janeiro: Civilização Brasileira, 2016.

DEMIER, Felipe. Depois do golpe: a dialética da democracia blindada no Brasil. 1. ed. Rio de Janeiro: Mauad X, 2017.

DUNKER, Christian Ingo L. Mal-estar, sofrimento e sintoma: uma psicopatologia do Brasil entre muros. 1. ed. São Paulo: Boitempo, 2015.

GRAMSCI, Antonio. Cadernos do cárcere - Volume 1: Introdução ao estudo da filosofia. A filosofia de Benedetto Croce. 4. ed. Rio de Janeiro: Civilização Brasileira, 2006.

KANG, Jaeho. O espetáculo da modernidade: a crítica da cultura de Walter Benjamin. Novos Estudos, CEBRAP, no 84, julho 2009. p. 215-233.

KONDER, Leandro. Walter Benjamin: o marxismo da melancolia. 3. ed. Rio de Janeiro: Civilização Brasileira, 1999.

LEMINSKI, Paulo. Toda poesia. 1. ed. São Paulo: Companhia das Letras, 2013.

LÖWY, Michael. Da tragédia à farsa: o golpe de 2016 no Brasil. In: Singer, André [et. al]. Jinkings, Ivana; Kim, Doria; Cleto, Murilo (orgs.). Por que gritamos golpe?: para entender o impeachment e a crise. 1. ed. São Paulo: Boitempo, 2016.

MITROVITCH, Caroline. Experiência e formação em Walter Benjamin. 1. ed. São Paulo: UNESP, 2011.

MTST. Por que ocupamos? Movimento dos Sem Teto: São Paulo, 2012.

OLIVEIRA, Francisco de. Hegemonia às avessas. In: BRAGA, Ruy; OLIVEIRA, Francisco de; RIZEK, Cibele (orgs.). Hegemonia às avessas: economia, política e cultura na era da servidão financeira. São Paulo: Boitempo, 2010. p. 21-27.

RANCIÈRE, Jacques. A partilha do sensível: estética e política. 2. ed. São Paulo: EXO experimental, Ed. 34, 2009. 
RANCIÈRE, Jacques. O ódio à democracia. 1. ed. São Paulo: Boitempo, 2014.

SARAMAGO, José. O Ano da Morte de Ricardo Reis. 6. ed. Lisboa: Caminho, 1984.

SINGER, André; LOUREIRO, Isabel (orgs.). As contradições do lulismo: a que ponto chegamos?. São Paulo: Boitempo, 2016.

ŽIŽEK, Slavoj. Acontecimento: uma viagem filosófica através de um conceito. 1. ed. Rio de Janeiro: Zahar, 2017.

\section{Notas}

${ }^{1}$ Que culminaram na deposição da presidenta Dilma Roussef, sob o pano de fundo do combate parcial, logo supostamente implacável da corrupção e seus efeitos.

${ }^{2}$ Movimento dos Trabalhadores Rurais Sem Terra.

${ }^{3}$ Movimento dos Trabalhadores Sem Teto.

${ }^{4}$ Provocadas, sobretudo, pelas medidas antipopulares empreendidas pelo governo Temer (2016-2017), com destaque para a PEC 241-55 (que congela por duas décadas os investimentos públicos em educação e saúde) e a MP 746/2016 (reforma do ensino médio que flexibiliza e precariza a oferta de disciplinas e o trabalho do professor, além de permitir que notórios saber ganhem centralidade no exercício da docência), que atingem diretamente a estrutura educacional pública brasileira.

${ }^{5}$ Com inúmeros projetos de lei tramitando no Congresso e em Assembleias Legislativas estaduais e municipais. Destacamos o projeto Escola Sem Partido (PL 867/2015) e o projeto que trata do assédio ideológico em sala de aula (PL 1411/2015), profundamente vinculados. Chama a atenção a profusão destas ações nos últimos três anos.

${ }^{6}$ A partir sobretudo do espetáculo das delações da Operação Lava-Jato, com destaque para o famoso episódio divulgado na grande mídia (17/05/2017) envolvendo os donos/gestores da megacorporação JBS, maior produtora de proteína animal do mundo, e o presidente Michel Temer. Disponível em: https://oglobo.globo. com/brasil/dono-da-jbs-grava-temer-dando-aval-para-compra-de-silencio-de-cunha-21353935 . Acesso em: jun. 2017.

7 "Achar

a porta que esqueceram de fechar.

O beco com saída.

A porta sem chave.

A vida."

(Leminski, 2013, p. 13)

${ }^{8}$ Expressão polissêmica de origem inglesa que designa aparelhos privados de hegemonia elaboradores de políticas, pesquisas, pedagogias, estratégias. De origem militar, o nome dilatou-se a partir do uso mais corrente, sobretudo a partir dos anos 1970, com a profusão de instituições da sociedade civil, supostamente autônomas e de "interesse social”, focalizadas na elaboração de consensos nas esferas política, econômica, 
* Professor doutor da Universidade do Estado do Rio de Janeiro, São Gonçalo, Rio de Janeiro, Brasil.

\section{Correspondência}

Carlos Eduardo Rebuá Oliveira - Universidade do Estado do Rio de Janeiro, Centro de Educação e Humanidades, Faculdade de Formação de Professores de São Gonçalo. Rua Francisco Portela, 1470, Patronato. CEP: 24435005. São Gonçalo, Rio de Janeiro, Brasil.

E-mail: rebua7@gmail.com

Recebido em 01 de julho de 2017

Aprovado em 14 de novembro de 2017 
